\title{
Dentoalveolar surgery techniques combined with orthodontic treatment: A literature review
}

\author{
F. Deniz Uzuner ${ }^{1}$, Nilufer Darendeliler ${ }^{1}$
}

Correspondence: Dr. F. Deniz Uzuner

Email: fduzuner@yahoo.com.tr

'Department of Orthodontics, Faculty of Dentistry, Gazi University, Ankara, Turkiye

\begin{abstract}
Surgery on the dentoalveolar process combined with orthodontic treatment was emphasized as an alternative method for reducing the treatment time and improving the orthodontic treatment on post-adolescent and adult patients. This combined treatment facilitates and accelerates orthodontic tooth movement. This article reviews the clinical practice in surgery-assisted orthodontic treatment in relation to historical perspective, indications and biological principles, as well as limitations and risks of dento-osseous surgical techniques, including dento-osseous osteotomy and/or ostectomy, dento-osseous microfracture, dento-osseous corticotomy, and/or corticoectomy, and dental distraction.
\end{abstract}

Key words: Corticotomy, dental distraction, dentoalveolar surgery, osteotomy

\section{INTRODUCTION}

In line with the goal of orthodontic treatment targeting improvement of the patient's life adjustment through enhancement of dentofacial functions and esthetics, reducing orthodontic treatment duration is an issue of importance, particularly for adults. ${ }^{[1-5]}$ In this regard, given this constant demand for shorter treatments, investigation of new approaches to boost orthodontic treatment efficiency by shortening the treatment time, and facilitating a therapeutic process without foregoing the optimal results, has become a primary goal of all areas of orthodontics, for getting equal or better results than the traditional treatments. ${ }^{[6]}$

Accordingly, bone manipulation via surgical intervention, including orthognathic (total or segmental correction of maxillofacial bones) and dentoalveolar (surgical approach limited to the dentoalveolar region, including a single tooth or a group of teeth and cortical and/or trabecular bone) surgery become intriguing for orthodontists based on the associated alteration in the bone biology of tooth movement. ${ }^{[6-11]}$
Orthodontic surgery is considered to expand the boundaries of conventional orthodontic treatment, shorten the treatment time, and improve a patient's appearance quickly, ${ }^{[12]}$ leading to a rapid movement of teeth that are orthodontically activated, in response to increased bone turnover and increased metabolism. ${ }^{[9]}$ Additionally, in adult orthodontics, surgery-assisted orthodontic treatment can be extremely helpful in movements that will normally not occur without this assistance or will be extremely slow, ${ }^{[1]}$ and avoid the unnecessary or difficult tooth movements, to reduce risk. $^{[12]}$

In this regard, there are a growing number of publications emphasizing surgery on the dentoalveolar process combined with orthodontic treatment as an alternative method for adolescents and adults. ${ }^{[10,13-75]}$ Evaluation of the up-to-date literature data reveals the main techniques used in orthodontic surgery to include dentoalveolar osteotomy (interdental osteotomy, subapical osteotomy), dentoalveolar ostectomy (interdental ostectomy, wegde-shaped ostectomy), dentoalveolar microfracture, dentoalveolar corticotomy, dentoalveolar corticoectomy, and dental distraction. ${ }^{9,10,13,15-75]}$

How to cite this article: Uzuner FD, Darendeliler N. Dentoalveolar surgery techniques combined with orthodontic treatment: A literature review.

Eur J Dent 2013;7:257-65.

Copyright $\odot 2013$ Dental Investigations Society.

DOI: $10.4103 / 1305-7456.110201$ 
Accordingly, the presentarticleaims to review theclinical practice in surgery-assisted orthodontic treatment in relation to historical perspective, indications and biological foundations for the clinical use, as well as limitations and risks of dentoalveolar surgical techniques, including dentoalveolar osteotomy and/or ostectomy, dentoalveolar microfracture, dentoalveolar corticotomy and/or corticoectomy, and dental distraction.

\section{Dentoalveolar osteotomy and/or ostectomy}

\section{Historical background and clinical practice}

Dentoalveolar osteotomy infers a complete section of the bone through both the cortex and medulla, with reliance on the attached muscles, mucosa, and periosteum for an adequate blood supply to the bone fragment and contained dental pulp. ${ }^{[21,26,37,41]}$ In this technique, the teeth are mobilized with their supporting structures and repositioned to the desired position either immediately during the surgical operation or after the surgery by applying orthodontic forces for a short time. ${ }^{[21,26,30,37,41]}$ Dentoalveolar ostectomy refers to a complete segmental resection of the bone surrounding a tooth, including both the cortical and trabecular layers, in an attempt to eliminate an adjacent periodontal pocket. ${ }^{[21,26,41]}$

Considering the literature evidence, in 1921, Cohn-Stock ${ }^{[24]}$ reported excision of the palatal bone overlying the roots of the maxillary teeth to facilitate retrusion of the teeth, with their mobilization along with their supporting structures, for immediate repositioning.

In 1931, Bichlmayr ${ }^{[9]}$ defined corticotomy-ostectomy application for patients older than 16 years to accelerate care and reduce relapse. Bichlmayr's method was directed primarily at facilitating the correction of maxillary protrusion by extraction of the first premolars, division of the palatal cortex overlying the incisors via palatal wedge-shaped osteotomies, and excision of the alveolar bone distal to the canines. Movement was then achieved by the use of activated removable orthodontic appliances.

Neuman ${ }^{[42]}$ modified Bichlmayr' ${ }^{[9]}$ method by performing labial septotomies that included division of the inter-radicular bone as well. Da Costa ${ }^{[26]}$ reported a combined application of frenectomy and maxillary ostectomy to close the midline diastema in more than 1000 patients, with achievement of treatment in a short term, with very few of complications. In his series, labial phrenectomy including palatal papilla was followed by interdental ostectomy via cutting of the bone between the central teeth using a thin drill. The surrounding central teeth were tied with a thick double layer ligature wire and mobilized to the space created by the ostectomy. Closure of the diastema was achieved by a two-sided collapse of the anterior hemiaxilla toward the midline.

Bell ${ }^{[21]}$ described a method of interdental and subapical osteotomy for the surgical-orthodontic management of interincisal diastema. Following phrenectomy, dissection of the mucoperiosteal flap, only at the vestibule, and resection of the wedge-shaped bone between the central teeth, by interdental ostectomy, were performed with interdental osteotomy at the interdental regions between the canine-lateral and central-lateral teeth using a fissure drill, and the deep cut extending to the palate was checked by direct mucosal palpation. The vertical cut was prolonged to pass $4 \mathrm{~mm}$ over the root apex and these vertical cuts were connected with a horizontal cut, yielding each tooth to become a tooth-bone segment, to be released and connected to the palatal mucoperiosteum only by completion of the cuts. The fixation consisted of ligation for seven weeks with edgewise appliances.

Peterson $^{[41]}$ described two cases of surgical repositioning of the teeth in the multidiastema by using the Bell ${ }^{[21]}$ technique, but with the use of an acrylic lingual splint instead of edgewise appliances for the fixation.

Merril and Pedersen ${ }^{[37]}$ as well as Epker and Paulus[ ${ }^{[29]}$ reported the application of osteotomy either in one stage or in two stages. One-stage surgery was reported to be applicable when the number of teeth to be moved was up to three. The two-stage procedure was preferable for a higher number of teeth and in case of close proximity to the roots, for closure of multiple large diastemas, for moving multiple small segments to a considerable distance, and for rotational movements of the segments.

The single-stage approach includes ${ }^{[29]}$ dissection of the buccal flap with interdental vertical cuts, extending from the buccal region to the pyriform aperture, where they can be unified by means of an anatomical space or by means of a horizontal cut to the inferior region of the nasal floor. After completion of the vertical or horizontal cuts, the newly formed tooth-bone segment is repositioned by finger pressure or mobilized for a certain period by application of orthodontic forces. Protection of tissue integrity, with palatal mucosa 
on at least one side, is strongly emphasized in the single-stage approach.

The second stage includes the initial dissection of the palatal flap and palatal bone osteotomy, and waiting for four to five weeks is recommended for maintenance of adequate blood supply despite the fact that the palatal mucosa appears well healed within seven to ten days. This initial phase is followed by labial osteotomy after three to four weeks in the second stage with mobilization and repositioning of the newly formed tooth-bone segment. ${ }^{[29]}$

Pros and cons of the technique

According to published reports on dentoalveolar osteotomy and/or ostectomy, the main indications were single application of the method in failure or rejection of the orthodontic treatment in adult patients, ${ }^{[21,37,41]}$ application in combination with the orthodontic treatment in repositioning of dentoalveolar elements, ${ }^{[37]}$ in shortening the length of the treatment period,,$^{[21,26,41]}$ in maxillary dentoalveolar protrusion if interproximal width is sufficient, ${ }^{[37]}$ in closure of diestamas, ${ }^{[21,26,37,41,46]}$ in repositioning of an ankylosed or endodontically treated tooth, ${ }^{[29,34,37]}$ in incisor intrusion, ${ }^{[21,37]}$ in case of crown-bridge application necessitating teeth alignment, but lacking adequate anchorage points for the desired tooth, and in extensive orthognatic surgeries, when small segment osteotomy is needed. ${ }^{[44]}$ Additionally, while periodontal diseases are considered a contraindication for dentoalveolar surgery, osteotomy was reported to be possible via osseous reconturing and use of hip bone marrow grafts. ${ }^{[37]}$

The downside is a concern about the side effects, such as, loss of tooth vitality, avascular necrosis in the bone segment, gingival recession, loss of crestal bone and pocket formation, delay in movement of the segment due to bone interferences, traumatic occlusion, and the typical risks of general anesthesia and hospitalization ${ }^{[11,22,29,37,41]}$ Besides, in severe crowding cases the risk of damage to the tooth root and complications regarding insufficient blood supply, due to reduction in the surrounding bone area, were reported to contraindicate the application of this technique. ${ }^{[30]}$

To prevent these complications, careful evaluation considering the proximity of the roots ${ }^{[12]}$ and careful surgical planning with cutting of the bone using small bone drills for obtaining the largest possible connection of bone segments, especially at the apex of the alveolar crest ${ }^{[41]}$ have been recommended during the surgical and retraction procedures. ${ }^{[12]}$ For ideal repositioning of the tooth-bone segment, application of trimming to the mobile segment or interproximal regions of the next tooth and performing occlusal adjustment if necessary, have been suggested. ${ }^{[29,37]}$ As completion of bone healing occurs within four to six weeks, immediate postsurgical mobilization of the segment via orthodontic forces must be completed within two to four weeks, in order to avoid loss of any advantages obtained by surgery. ${ }^{[2,37]}$

\section{Dentoalveolar microfracture techniques}

Historical background and clinical practice

In this technique after applying interdental and horizontal cuts, the final movement of the dentoalveolar segment was done by the fractures, with the help of osteotomes. Medeiros and Bezerra ${ }^{[36]}$ reported surgical repositioning of an ankylosed upper central tooth by interdental osteotomy in a ten-year-old girl. Dissection of the flap was performed only from the labial region, while interdental osteotomy was performed via a vertical cut extending from the mesial and distal parts of the central tooth to the palatal cortex. Following mobilization of the tooth with artificial fractures, the newly formed tooth-bone segment was placed toward the occlusal plane and attached with an arch wire. The researchers indicated healthy bone and soft tissue after eight months of therapy. ${ }^{[36]}$

Kral and Subrt ${ }^{[47]}$ reported the success of a combined application of corticotomy and alveolar microfracture formation to shorten the length of treatment in teeth having a palatal position in 15 patients, with maintenance of tooth vitality after the treatment. Two vertical corticotomy cuts extending from the buccal and lingual at the mesial and distal part of the tooth below the crest apex to the tip of the root were performed under infiltrative anesthesia. Afterward, the upper part of the root tip was held with an incisor clamp and an artificial fracture was created. The tooth-bone segment formed in this manner was slid to the desired location and fixed for three to four weeks, by being connected to two teeth from both sides, using the Sauer's arch bars.

Different from Kral and Subrt, ${ }^{[47]}$ Fitzpatrick $^{[30]}$ described a technique that included repositioning of the tooth-bone segment by orthodontic forces, with addition of a horizontal cut, which passed far from the teeth roots in the apical regions. With regard to the blood supply, the use of this technique in the upper jaw, even in patients younger than 20 years of age, has been suggested to be much safer. 
Pros and cons of the technique

Medeiros and Bezerra ${ }^{[36]}$ indicate that single-tooth dento-osseous osteotomy is a feasible procedure for upper ankylosed teeth because of the favorable vascularity of the maxilla. Several authors ${ }^{[29,48,49]}$ have stressed the importance of keeping the soft tissue pedicles attached to the cortices, especially the labial pedicle, in this type of procedure, which requires very gentle handling of the hard and soft tissues, to avoid necrosis. In addition, this procedure seems to have a better application to the upper anterior teeth. The tooth to be repositioned must be in a vertical position, with a necessary minimum space of $2 \mathrm{~mm}$ between its root and the adjacent teeth. Plaster models are suggested to establish the feasibility of the procedure and allow the surgeon to make an acrylic splint to stabilize the osteotomized segment. ${ }^{[36]}$

\section{Dentoalveolar corticotomy and/or corticoectomy}

Historical background and clinical practice

Corticotomy has its roots in orthopedics going back to the early 1900s. ${ }^{[50]}$ The first reports on surgical approaches to correct the poorly positioned teeth are assigned to L. C. Brian, in 1892, and G. Cunningham, in 1893. ${ }^{[37]}$ The former defined it as a linear cutting technique in the cortical plates surrounding the teeth, to produce mobilization of the teeth for immediate movement, ${ }^{[30]}$ and reported such cases at the Meeting of the American Dental Society of Europe, and the latter presented the possibility of immediate correction of irregular teeth during the Dental Conference in Chicago that year. ${ }^{[37]}$

In 1931, Bichlmayr ${ }^{[9]}$ reported the application of corticotomy for enhancing the retrusion of the upper jaw protrusive teeth in patients older than 16 years of age, in order to accelerate the therapeutic process and reduce the likelihood of relapse, with accomplishment of teeth movement by using removable orthodontic appliances postoperatively. Bichlmayr ${ }^{[9]}$ also reported the expansion provided by corticotomy applied to the buccal region of premolar and molar teeth in patients with bilaterally narrow maxilla, with substantial influence in the dental society, leading to the acceptance of corticotomy in German-speaking European countries as the 'Bichlmayr method'.

In 1959, Kole ${ }^{[10]}$ introduced a surgical procedure that involved the reflection of full thickness flaps to expose the buccal and lingual alveolar bone, followed by interdental cuts through the cortical bone, barely penetrating the medullary bone (corticotomy style). The subapical horizontal cuts connecting the interdental cuts were osteotomy style, penetrating the full thickness of the alveolus. He suggested that, as the blocks of bone were moved rather than the individual teeth, root resorption would not occur and retention time would be minimized. Even as this theory of en bloc movement to enhance tooth movement prevailed in several subsequent reports, ${ }^{[50]}$ this treatment approach never gained widespread acceptance, probably due to its invasive nature as well as the association of horizontal subapical osteotomies, which posed considerable risks to the periodontium and tooth pulp vitality. ${ }^{[6,7,22]}$

In 1975, Düker ${ }^{[27]}$ performed the first animal study replicating the technique described by Köle ${ }^{[10]}$ on beagle dogs, to investigate how rapid tooth movement with corticotomy affects the vitality of the teeth and the marginal periodontium. The health of the periodontium was preserved by avoiding the marginal crest bone during the corticotomy cuts. In conclusion, neither the pulp nor the periodontium was damaged following orthodontic tooth movement after the corticotomy surgery, which helped to substantiate the belief regarding the health of the crestal bone in relation to the corticotomy cuts. All the subsequent techniques have taken into consideration that the interdental cuts must always be done at least $2 \mathrm{~mm}$ below the alveolar crestal bone level. ${ }^{[7]}$

A few years later, the supra-apical connecting osteotomy cuts used by Köle ${ }^{[10]}$ were replaced by cuts limited to the cortical portion of the alveolar bone. ${ }^{[11]}$ Hence, the first description of a surgical attempt to enhance orthodontic treatment using only corticotomies thereby reduces the risks inherent in the previous approach. Furthermore, the use of fixed orthodontic appliances increases the control and efficiency afforded by this therapeutic combination. ${ }^{[17,51]}$

Suya ${ }^{[17]}$ reported corticotomy-assisted orthodontic treatment of 395 adult Japanese patients, in 1991. Suya's technique differed from Kole's with the substitution of subapical horizontal corticotomy cuts in place of the horizontal osteotomy cut beyond the apices of the teeth. Fixed orthodontic appliances were used with completion of the treatment in six to twelve months He believed that the tooth movements were made by moving blocks of bone using the crowns of the teeth as handles and for this, heavy forces had to be applied so as to move the bony blocs. He advised $200 \mathrm{~g} / \mathrm{cm}^{2}$ of anteroposterior force for completion of tooth movement in three to four months, after which 
time the edges of the blocks of bone would begin to fuse together. ${ }^{[7]}$

The force magnitude for corticotomy-assisted tooth movement is still controversial. Nakanishi, ${ }^{[39]}$ investigated the effects of various loads and of osteotomy and corticotomy on orthodontic tooth movement, on experimental dogs, and reported that a load of $800 \mathrm{~g}$ caused greater tooth movement than a load of $200 \mathrm{~g}$. In contrast, in another experimental study Itoh et al. ${ }^{[15]}$ reported that orthodontic tooth movement was caused by a light force $(160 \mathrm{~g})$, as the main resistance was reduced and the remodeling of the surrounding bone was facilitated.

Nevertheless, the use of alveolar corticotomies as an aid to orthodontic therapy remained limited until the last decade. ${ }^{[6]}$ A more recent surgical orthodontic therapy was introduced by Wilcko et al., ${ }^{[11,52,54,55]}$ which included the innovative strategy of combining corticotomy surgery with alveolar grafting in a technique referred to as Accelerated Osteogenic Orthodontics (AOO) ${ }^{[52,54,55]}$ and more recently as Periodontally Accelerated Osteogenic Orthodontics (PAOO).$^{[11]}$ This technique is advocated for comprehensive fixed orthodontic appliances in conjunction with movement of full thickness flaps and labial and lingual corticotomies around the teeth. The bone graft consisting of demineralized freeze-dried bone and bovine bone with clindamycin was applied directly over the bone cuts and the flap was sutured in place. Tooth movement was initiated two weeks after the surgery, and every two weeks thereafter, by activation of the orthodontic appliance. Wilcko et al. ${ }^{[11,52,54,55]}$ reported that this technique would reduce treatment time to one-third the time of conventional orthodontics, ${ }^{[7]}$ which was attributed to a state of reduced mineralization (reversible osteopenia) of the alveolar bone surrounding the involved teeth during the orthodontic movement and not to the bony block movement, as claimed by Köle ${ }^{[10]}$ and Suya. ${ }^{[17]}$ Wilcko ${ }^{[55]}$ explained the concept of reversible osteopenia in a study of five patients, using computed tomographic imaging. After corticotomy, demineralization occurs in the alveolar bone and the remaining collagenous matrix of the bone is transported with the tooth during its movement. The matrix then remineralizes following orthodontic movement. This introduced new concepts to the corticotomy-assisted orthodontic treatment (CAOT) field, including bone matrix transportation and osteopenia-facilitated rapid tooth movement. ${ }^{[55]}$
Additionally, Wang et al. ${ }^{[56]}$ conducted a study on an animal model for corticotomy and osteotomy-assisted tooth movement in the rat and indicated that alveolar corticotomies and osteotomies produced different bone responses based on the results of computerized tomograms. Corticotomies and corticotomy-assisted tooth movement produced transient bone resorption around the dental roots similar to what Yaffe et al. ${ }^{[57]}$ reported, as a regional acceleratory phenomenon. This temporary loss of supporting the alveolar bone around the dental roots was not observed with osteotomies or osteotomy-assisted tooth movement. Instead, a distal distraction site was formed with osteotomy-assisted tooth movement. A histological study to examine the underlying cellular responses to corticotomy and osteotomy-assisted tooth movements in rats by Wang et al. ${ }^{[58]}$ concluded that corticotomy-assisted tooth movement produced transient bone resorption around the dental roots under tension; this was replaced by fibrous tissue after 21 days and by bone after 60 days. Osteotomy-assisted tooth movement resembled distraction osteogenesis and did not pass through a stage of regional bone resorption. Mostafa et al. ${ }^{[59]}$ conducted a study to identify the effect of the corticotomy-facilitated (CF) technique on orthodontic tooth movement and compared it with the standard technique, to explore the histological basis of the difference between the two techniques. They concluded that the CF technique doubled the rate of orthodontic tooth movement. Histologically, the more active and extensive bone remodeling in the CF group suggested that the acceleration of tooth movement associated with corticotomy was due to increased bone turnover and was based on a regional acceleratory phenomenon. ${ }^{[8]}$

Pros and cons of the technique

Overall, the indications for the use of alveolar corticotomies (ACS) in orthodontics have been grouped into three main categories; (a) to accelerate corrective orthodontic treatment, as a whole, (b) to facilitate the implementation of mechanically challenging orthodontic movements, and (c) to enhance the correction of moderate-to-severe skeletal malocclusions. ${ }^{[6]}$

The advantages of the PAOO procedure that have been reported are: (a) The reduction of treatment time being half to one-third of the time taken by conventional orthodontics, (b) less root resorption, due to decreased resistance of the cortical bone, (c) more bone support due to the addition of bone graft, ${ }^{[11,52,54,55]}(\mathrm{d})$ very low incidence of relapse ${ }^{[5,11,52,54,55,60,61]}$ and (e) less need for 
extra-oral appliances and headgear. ${ }^{[11,52,54,55]}$ The PAOO technique has its roots in orthodontic research and practice, ${ }^{[5,11,27,33,52,54,55,60,61]}$ with good patient outcomes in the ten years since its first application. ${ }^{[11,52,54,55]}$ It has been confirmed to be useful in accelerating the rate of individual tooth or dental segment movement, that is, canine ${ }^{[45,53,60]}$ and incisor retraction, ${ }^{[7]}$ eruption of impacted teeth, slow orthodontic expansion, molar intrusion, open bite correction, and the control of anchorage. ${ }^{[50]}$

Despite an increasing number of reports on the use of alveolar corticotomies as an aid to orthodontic treatment, few studies have reported the setbacks when employing this combined treatment. Recently, however, Wilcko et al. ${ }^{[62]}$ gave an objective account of the scenarios where the use of ACS-orthodontics should be avoided. These included, (a) patients showing any sign of active periodontal disease, (b) individuals with inadequately treated endodontic problems, (c) patients having a prolonged use of corticosteroids, (d) persons who are taking any medications that slow down bone metabolism, such as bisphosphonates and nonsteroidal anti-inflammatory drugs (NSAIDs). ${ }^{[6]}$

Patients with active periodontal disease or gingival recession are not good candidates for CAOT, which also must not be considered as an alternative for surgically-assisted palatal expansion in the treatment of severe posterior cross-bite and must not be used in cases where bimaxillary protrusion is accompanied with a gummy smile, which might benefit more from segmental osteotomy. ${ }^{[63]}$

Although CAOT may be considered a less-invasive procedure than osteotomy-assisted orthodontics, there have still been several reports regarding the adverse effects to the periodontium after corticotomy, ranging from no problems ${ }^{[27,64,65]}$ to slight interdental bone loss and loss of attached gingiva, ${ }^{[66]}$ to periodontal defects observed in some cases, with short interdental distance. ${ }^{[67]}$ Subcutaneous hematomas of the face and the neck have been reported after intensive corticotomies, while postoperative swelling and pain is expected for several days. However, no effect on the vitality of the pulp in the teeth, in the area of the corticotomy, has been reported. ${ }^{[68,69]}$ Pulp vitality deserves additional investigation, as long-term research on pulpal vitality after rapid movement has not been evaluated in the literature. ${ }^{[50]}$

Although many authors defined that corticotomy can prevent root resorption and no resorption was observed, ${ }^{[5,10,53]}$ considerable amount of apical resorption was reported by Gantes et al., ${ }^{[16]}$ which indicated it to be likely in the classical orthodontic tooth movement also. Hence, knowing that the reduced treatment duration of CAOT may reduce the risk of root resorption, the long-term effect of CAOT on root resorption requires further study. ${ }^{[50]}$

\section{Dental distraction}

Historical background and clinical practice

Mechanical stretching of the reparative bone tissue by a distraction device, through an osteotomy or corticotomy site, is the most common technique in distraction osteogenesis. ${ }^{[70-72]}$ With this technique, new bone is generated in the gap of the osteotomy or corticotomy at the approximate rate of $1 \mathrm{~mm}$ per day. Another well-known modality of distraction osteogenesis is through a suture, such as in rapid palatal expansion, ${ }^{[73]}$ in which the hard palate is distracted transversely through the midpalatal suture $1 \mathrm{~mm}$ per day. Liou and Huang ${ }^{[13]}$ applied the distraction osteogenesis concept to the orthodontic tooth movement, which was called 'dental distraction'. They stated that the periodontal ligament was a suture between the alveolar bone and tooth and the process of osteogenesis in the periodontal ligament during orthodontic tooth movement was similar to that in the midpalatal suture during rapid palatal expansion. In their previous study, Liou et al. ${ }^{[75]}$ created edentulous spaces using an intraoral distraction device in the mandible of mature Beagle dogs between the third and fourth premolars and tried to move the fourth premolars into the edentulous space. They observed that the best time to initiate orthodontic tooth movement was when the edentulous space was fibrous and bone formation had just begun.

In 1998, Liou and Huang ${ }^{[13]}$ demonstrated the rapid distalization of canine teeth in humans using distraction of the periodontal ligament. The surgery was performed to the first premolar's extraction socket. At the time of the first premolar extraction the interseptal bone distal to the canine was undermined with a bur, grooving vertically inside the extraction socket along the buccal and lingual sides and extending obliquely toward the socket base. Then a tooth-borne, custom-made, intraoral distraction device was placed to distract the canine distally. It was activated 0.5 to $1.0 \mathrm{~mm}$ / day immediately after the extraction. They achieved an average of $6.5 \mathrm{~mm}$ distraction of the canines within three weeks. The radiographic examination revealed that apical or 
lateral surface root resorption of the canine was minimal; due to the fact that the distraction was nearly completed by the time the external root resorption was just being initiated. No periodontal defect or endodontic lesion was observed throughout and after distraction.

Similarly, Sayın et al. ${ }^{[74]}$ used the dental distraction method on 43 canines in 18 patients. By using semi-rigid, individual tooth-borne distractors, which were activated to $0.25 \mathrm{~mm}$, three times a day during three weeks; they achieved $5.76 \mathrm{~mm}$ and $3.5 \mathrm{~mm}$ canine distalization in the maxilla and mandible, respectively, with minimal anchorage loss. Fractures were observed in the interseptal bone adjacent to the apex of the canine in some of the periapical radiographs, indicating a considerable resistance to the applied force. It was considered that this might increase the potential tipping movement and the extrusive effect of the mechanism by causing the canine's center of resistance to move closer to the apex. They concluded that reducing the entire thickness of the interseptal bone between the canine and first premolar would be more useful in minimizing the undesired tipping and extrusion movements of the canine teeth.

\section{Pros and cons of the technique}

Even as this new concept and technique is best used in cases where anterior teeth are severely crowded or protruded, the clinical techniques and procedures in canine distraction still need to be refined. The long-term effects on root resorption, the subsequent development of a developing root, pulp vitality, periodontal tissues, and possible root ankylosis of the canine must be closely monitored. ${ }^{[13]}$

In addition to orthodontic tooth movement, this new concept and technique may possibly be used to generate new bone and keratinized gingival tissue for treating periodontal disease. ${ }^{[20]}$

\section{CONCLUSION}

Dentoalveolar surgical intervention in orthodontic treatment of adult patients is a promising technique, with many applications. The advantages of the pre-mentioned technique are as follows: (a) Less treatment time, (b) avoidance of potential periodontal complications, (c) favorable direction of growth, and (d) extensive envelope of the tooth movement. ${ }^{[18-74]}$ In this regard, different supportive surgical methods have been reported for the movement of an individual tooth or groups of teeth in the literature, with respect to the severity of malocclusion and the type and direction of the desired movement. ${ }^{[6-15,18-74]}$

Shortening the length of the treatment period, ${ }^{[21,26,41]}$ improving the orthodontic treatment in post-adolescent and adult patients, ${ }^{[10,15,16-18,21,26,33,37,41]}$ maxillary dentoalveolar protrusion, ${ }^{[37]}$ retraction of protrusive incisives, ${ }^{[33]}$ retraction of canine ${ }^{[10,13,45,53,74]}$ polidiestamas, ${ }^{[41,46,57,61,62,64,21,26,37,41,42,44]}$ optimal repositioning of the ankylosed teeth, ${ }^{[37,49,54,57,17,29,34,37]}$ intrusion of the molars, incisives, ${ }^{[41,53,57,64,21,33,37,44]}$ maxillar expansion, ${ }^{[31,38,43]}$ and the reduction of the relapse ${ }^{[18,33]}$ were reported among the indications for surgery-assisted orthodontic treatment.

Surgery-directed injuries in the bone via fractures, osteotomies or corticotomies cause a change in the metabolism leading to the regional accelerating phenomenon (RAP), including increase in osteoclasts, osteoblasts, mediators, and cell precursors of the blood and lymph vessels in the injured area, which positively promote the speed of orthodontic movement caused by transient osteopenia, as maintained by the permanent orthodontic forces. ${ }^{[29,11]}$

Accordingly, there is a growing interest in the use of dentoalveolar surgery as an adjunct to orthodontic treatment due to a comprehensive understanding of its effects and more solid evidence-based research, revealing a possibility of enhancing certain orthodontic movements via the impact of the biological stimulus generated by surgery in the dentoalveolar bone. ${ }^{[6]}$

Although the effects and mechanisms of dentoalveolar surgery techniques have been confirmed by recent well-designed histological studies, further randomized testing in humans is still necessary to confirm the claimed advantages of these techniques and to evaluate the long-term effects. ${ }^{[50]}$ Moreover, because the use of dentoalveolar surgery as an aid to orthodontic treatment remains limited until the present time, due possibly to their invasive nature, further research for less invasive procedures must be encouraged. ${ }^{[6]}$

\section{REFERENCES}

1. Midgett RJ, Shage R, Fruge JF. The effect of altered bone metabolism on orthodontic tooth movement. Am J Orthod 1981;80:256-62.

2. Cedro MK, Moles DR, Hodges SJ. Adult orthodontics-who's doing what? J Orthod 2010;37:107-17.

3. Bridges T, King G, Mohammed A. The effect of age on tooth movement and mineral density in the alveolar tissues of the rat. Am J Orthod Dentofac Orthop 1988;93:245-50.

4. Dyer GS, Harris EF, Vaden JL. Age effects on orthodontic treatment: 
Adolescents contrasted with adults. Am J Orthod Dentofac Orthop 1991;100:523-30.

5. Robb SI, Sadowsky C, Schneider BJ, BeGole EA. Effectiveness and duration of orthodontic treatment in adults and adolescents. Am J Orthod Dentofac Orthop 1998;113:383-6.

6. Oliveira DD, de Oliveira BF, Soares RV. Alveolar corticotomies in orthodontics: Indications and effects on tooth movement. Dental Press J Orthod 2010;15:144-57.

7. AlGhamdi AS. Corticotomy facilitated orthodontics: Review of a technique. Saudi Dent J 2010;22:1-5.

8. Abbas IT, Moutamed GM. Acceleration of orthodontic tooth movement by alveolar corticotomy using piezosurgery. J Am Sci 2012;8:13-19.

9. Bichlmayr A. Chirurgische Kieferorthopaedie und das Verhalten des Knochens und der Wurselspitzen nach derselben. Dtsch Zahnaerztl Wschr 1931;34:835-42.

10. Köle H. Surgical operations on the alveolar ridge to correct occlusal abnormalities. Oral Surg Oral Med Oral Pathol 1959;12:515-29.

11. Wilcko MT, Wilcko WM, Bissada NF. An evidence-based analysis of periodontally accelerated orthodontic and osteogenic techniques: A synthesis of scientific perspective. Semin Orthod 2008;14: 305-16.

12. Chung KR, Kim SH, Lee BS. Speedy surgical-orthodontic treatment with temporary anchorage devices as an alternative to orthognathic surgery. Am J Orthod Dentofac Orthop 2009;135:787-98.

13. Liou EJW, Shing Huang C. Rapid canine retraction through distraction of the periodontal ligament. Am J Orthod Dentofac Orthop 1998;114:372-82.

14. Ren A, Lv T, Kang N, Zhao B, Chen Y, Bai D. Rapid orthodontic tooth movement aided by alveolar surgery in beagles. Am J Orthod Dentofacial Orthop 2007;131:160.e1-10.

15. Itoh T, Nakazima M, Arita S, Nakagawa M, Kawagoe H, Fujita N, et al. Experimental study on the tooth movement with corticotomy procedure. Nippon Kyasei Shika Gakkai Zasshi 1981;40:92-105.

16. Gantes B, Rathbun E, Anholm M. Effects on the periodontium following corticotomy-facilitated orthodontics: Case reports. J Periodontol 1990;61:234-8.

17. Suya H: Corticotomy in orthodontics. In: Hosl E, Baldauf A, editors. Mechanical and Biological Basis in Orthodontic Therapy. Heidelberg, Germany: Huthig Buch Verlag; 1991. p. 207-26.

18. Anholm M, Crites DA, Hoff R, Rathbun WE. Corticotomy-facilitated orthodontics. Calif Dent Assoc J 1986;14:7-11.

19. Ascher F. Zur spaetbehandlung der Prognathie des oberkiefers. Dtsch Zahnaerztl Z 1947;2:218-26.

20. Bell WH. Revascularization and bone healing after anterior maxillary osteotomy, a study using adult rhesus monkeys. J Oral Surg 1969;27:249-55.

21. Bell WH. Surgical-orthodontic treatment of interincisal diastemas. Am J Orthod 1970;57:158-62.

22. Bell W, Levy B. Revascularization and bone healing after maxillary corticotomies. J Oral Surg 1972;30:640-8.

23. Byloff-Clar H. Vergleichende histologische untersuchungen bei behandlung von spätfällen mit und ohne kortikotomie. Fortschr-Kieferorthop 1966;27:204-19.

24. Cohn-Stock G. Die chirurgische immediatregulierung. der Kiefer Vjschr Zahnhk 1921;37:320; es quated Merrill RG, Pedersen GW. Interdental osteotomy for immediate repositioning of dental osseous elements. J Oral Surg 1976;34:118-25.

25. Cunningham G. Methode sofortiger Regulierung von anomales 2 jahn-stellungen', Oester-Ung Vjschr Zahnheilk 1984;10:455-7; es quated Anholm M, Crites DA, Hoff R, Rathbun WE. Corticotomy-Facilitated Orthodontics. Calif Dent Assoc J 1986;14:7-11.

26. DaCosta C. Immediate closure of labial diastema by frenectomy and maxillary ostectomy. J Oral Surgery 1968;26:273-6.

27. Düker J. Experimental animal research into segmental alveolar movement after corticomy. J Max Fac Surg 1975;3:81-4.

28. Düker J. Histological studies on rapid dental group movements following corticotomy in the animal experiment. Fortschr Kiefer Gesichtschir 1976;21:72-4.

29. Epker BN, Paulus PJ. Surgical-orthodontic correction of adult malocclusion single tooth dento-osseous osteotomies. Am J Orthod 1978;74:551-63.

30. Fitzpatrik BN. Corticotomy. Aust Dent J 1980;25:255-8.

31. Glassman AS, Nahigian SJ, Medway JM, Aronowitz HI. Conservative surgical orthodontic adult rapid palatal expansion: Sixteen cases. Am J Orthod 1984;86:207-13.
32. Guilford SH. Orthodontia or malposition of the human teeth; its prevention and remedy. Philadelphia: Press of T.C.Davis and Sons; 1898. es quated Anholm M, Crites DA, Hoff R, Rathbun WE. Corticotomy-facilitated Orthodontics. Calif Dent Assoc J 1986;14:7-11.

33. Kerdvongbundit V. Corticotomy facilitated orthodontics. J Dent Assoc Thai 1990;40:284-91.

34. Patrikiou AK, Katsavrias EG. Repositioning ankylosed maxillary canines by segmental osteotomy. J Clin Orthod 1995;29:625-8.

35. Lines PA. Adult rapid maxillary expansion with corticotomy. Am J Orthod 1975;67:44-56.

36. Medeiros PJ, Bezerra AR. Treatment of an ankylosed central incisor by single-tooth dento-osseous osteotomy. Am J Orthod Dentofac Orthop 1997;112:496-501.

37. Merrill RG, Pedersen GW. Interdental osteotomy for immediate repositioning of dental-osseous elements. J Oral Surg 1976;34:118-25.

38. Mossaz CF, Byloff FK, Richter M. Unilateral and bilateral corticotomies for correction of maxillary transverse discrepancies. Eur J Orthod 1992;14:110-6.

39. Nakanishi H. Experimental study on artificial tooth movement with osteotomy and corticotomy (author's transl.). Shikwa-Gakuho 1982;82:219-52.

40. Neumann D. Die Bichlmayrsche Keilresektion bei der kieferorthopaedishen Spaetbehandlung', Fortschr Kiefer Gesichtschir 1955;1:206-10.

41. Peterson LJ. Immediate surgical closure of multiple maxillary diastemas. J Oral Surg 1972;31:522-7.

42. Stadelmann W. Orthodontic closure of gaps in the maxillary anterior region in combination with the Kole corticotomy in a 21-year-old patient (case report)]. Quintessenz Zahntech 1985;11:547-9.

43. Wintner MS. Surgically assisted palatal expansion. An important consideration in adult treatment. Am J Orthod Dentofac Orthop 1991;99:85-90.

44. Spilka CJ, Mathews PH. Surgical closure of diestama of central incisors. Am J Orthod 1979;76:443-7.

45. Aboul-Ela SM, El-Beialy AR, El-Sayed KM, Selim EM, El-Mangoury NH, Mostafa YA. Miniscrew implant-supported maxillary canine retraction with and without corticotomy-facilitated orthodontics. Am J Orthod Dentofacial Orthop 2011;139:252-9.

46. Cha YM, Park NS, Bayome M, Han SH, Kim Y, Kook Y. The frontal soft tissue changes in the lower facial portion after orthodontic treatment combined with anterior segmental osteotomy. Orthodontics (Chic) 2011;12:232-41.

47. Král A, Subrt I. Repositioning of a single tooth by means of corticotomy and fracturing of its alveolar process. Osterr Z Stomatol 1966;63:235-8.

48. Bell WH, Protfit WR. Maxillary excess. In: Bell WH, Prolfit WH, White RP, editors. Surgical correction of dentofacial deformities. Philadelphia: WB Saunders; 1980. p. 234-441.

49. Epker BN, Wolford LM. Dentofacial deformities--surgical--orthodontic correction. St Louis: CV Mosby; 1980. p. 192-206.

50. Hassan AH, Al-Fraidi AA, Al-Saeed SH. Corticotomy-assisted orthodontic treatment: Review. Open Dent J 2010;4:159-64.

51. Generson RM, Porter JM, Zell A, Stratigos GT. Combined surgical and orthodontic management of anterior open bite using corticotomy. J Oral Surg 1978;36:216-9.

52. Wilcko WM, Wilcko T, Bouquot JE, Ferguson DJ. Rapid orthodontics with alveolar reshaping: Two case reports of decrowding. Int J Periodontics Restorative Dent 2001;21:9-19.

53. Uzuner FD. Evaluating the effect of corticotomy in tooth movements applied to canine during canine retraction phase of fixed orthodontic treatment. Unpublished master's thesis. Turkey: Gazi University Faculty of Dentistry, Department of Orthodontics; 2000.

54. Wilcko WM, Wilcko MT, Bouquot JE, Ferguson DJ. Accelerated orthodontics with alveolar reshaping. J Ortho Practice 2000;10:63-70.

55. Wilcko MW, Ferguson DJ, Bouquot JE, Wilcko MT. Rapid orthodontic decrowding with alveolar augmentation: Case report. World J Orthod 2003;4:197-205.

56. Wang L, Karapetyan G, Moats R, Yamashita DD, Moon HB, Ferguson DJ, et al. Corticotomy-/osteotomy-assisted tooth movement micro CTs differ. J Dent Res 2008;87:861-7.

57. Yaffe A, Fine N, Binderman I. Regional accelerated phenomenon in the mandible following mucoperiosteal flap surgery. J Periodontal 1994;65:79-83.

58. Wang L, Lee W, Lei DL, Liu YP, Yamashita DD, Yen SL. Tisssue responses in corticotomy- and osteotomy-assisted tooth movements 


\section{Uzuner and Darendeliler: Dentoalveolar surgery combined orthodontics}

in rats: Histology and immunostaining. Am J Orthod Dentofacial Orthop 2009;136:770.e1-770.

59. Mostafa YA, Fayed MM, Mehanni S, ElBokle NN, Heidere AM. Comparison of corticotomy-facilitated vs standard tooth-movement techniques in dogs with miniscrews as anchor units. Am J Orthod Dentofacial Orthop 2009;136:570-7.

60. Fischer TJ. Orthodontic treatment acceleration with corticotomy-assisted exposure of palatally impacted canines. Angle Orthod 2007;77:417-20.

61. Nowzari H, Yorita FK, Chang HC. Periodontally accelerated osteogenic orthodontics combined with autogenous bone grafting. Compend Contin Educ Dent 2008;29:200-6.

62. Wilcko MT, Wilcko MW, Pulver JJ, Bissada NF, Bouquot JE. Accelerated osteogenic orthodontics technique: A 1-stage surgically facilitated rapid orthodontic technique with alveolar augmentation. J Oral Maxillofac Surg 2009;67:2149-59.

63. Lee JK, Chung KR, Baek SH. Treatment outcomes of orthodontic treatment, corticotomy-assisted orthodontic treatment, and anterior segmental osteotomy for bimaxillary dentoalveolar protrusion. Plast Reconstr Surg 2007;120:1027-36.

64. Iino S, Sakoda S, Miyawaki S. An adult bimaxillary protrusion treated with corticotomy-facilitated orthodontics and titanium miniplates. Angle Orthod 2006;76:1074-82.

65. Nishida M, Iizuka T, Itoi S, Hyo Y, Ono T. Clinical study of corticotomy by Kole's method. J Jpn Oral Surg Soc 1986;3:81-4.

66. Kwon HJ, Pihlstrom B, Waite D. Effects on the periodontium of vertical bone cutting for segmental osteotomy. J Oral Maxillofac Surg 1985;43:952-5.

67. Dorfman HS, Turvey TA, Hill C. Alterations in osseous crestal height following interdental osteotomies. Oral Surg Oral Med Oral Pathol 1979;48:120-5.

68. Ozturk M, Doruk C, Ozec I, Polat S, Babacan H, Bicakci AA. Pulpal blood flow: Effects of corticotomy and midline osteotomy in surgically assisted rapid palatal expansion. J Craniomaxillofac Surg
2003;31:97-100

69. Liou EJ, Figueroa AA, Polley JW. Rapid orthodontic tooth movement into newly distracted bone after mandibular distraction osteogenesis in a canine model. Am J Orthod Dentofacial Orthop 2000;117:391-8.

70. Snyder CC, Levine GA, Swanson HM, Browne EZ Jr. Mandibular lengthening by gradual distraction: Preliminary report. Plast Reconstr Surg 1973;51:506-8.

71. McCarthy JG, Schreiber J, Karp N, Thorne CH, Grayson BH. Lengthening the human mandible by gradual distraction. Plast Reconstr Surg 1992;89:1-10.

72. Polley JW, Figueroa AA. Management of severe maxillary deficiency in childhood and adolescence through distraction osteogenesis with an external, adjustable, rigid distraction device. J Craniofac Surg 1997;8:181-5.

73. Haas AJ. Palatal expansion: Just the beginning of dentofacial orthopedics. Am J Orthod 1970;57:219-55.

74. Sayın S, Bengi O, Gurton U, Ortakoglu K. Rapid canine distalization using distraction of the periodontal ligament. A preliminary clinical validation of the original technique.' Angle Orthod 2003;74:304-15.

75. Liou EJ, Polley JW, Figueroa AA. Distraction osteogenesis: The effects of orthodontic tooth movement on distracted mandibular bone. J Craniofac Surg 1998;9: 564-71.

\begin{tabular}{|l|l|}
\hline \multicolumn{2}{|c|}{ Access this article online } \\
\hline Quick Response Code: & Website: \\
& www.eurjent.com \\
& \\
&
\end{tabular}

